\title{
Motivation theory in the school context: differences in preservice and practicing teachers' experience, opinion, and knowledge
}

\author{
Linda Schürmann $^{1}$ (D) $\cdot$ Robert Gaschler ${ }^{2} \cdot$ Claudia Quaiser-Pohl $^{1}$
}

Received: 30 January 2020 /Revised: 16 June 2020 / Accepted: 10 August 2020 /

Published online: 2 September 2020

(C) The Author(s) 2020

\begin{abstract}
Preservice teachers should learn about motivation theory during their university studies in order to be able to motivate their students in their future job. Thus, this study had two objectives. First, it explored whether experience in education sciences and a motivation theory seminar were related to preservice teachers' perceived experience with motivation theory, their perceived and actual knowledge about it, and the relevance they assigned to it. Second, it investigated whether there were differences to practicing teachers. We administered a questionnaire on three motivational theories to $N=322$ to preservice and practicing teachers. We asked for the participants' experience with the topics, the relevance they assigned to them in the school context, and their perceived knowledge about them. Overall, preservice teachers rated motivation theory as relevant but displayed low experience with and knowledge about it. Visiting a seminar on motivation theory was connected to the highest values for all variables. Practicing teachers appeared more critical of motivation theory than preservice teachers. They assigned less relevance to it, although they displayed higher levels in perceived knowledge than preservice teachers without a motivation theory seminar background. Results suggest that there is a difference between the preservice and the practicing phase of teaching regarding motivation theory. Preservice teachers viewed the topic differently than practicing teachers. However, preservice teachers should know and be able to use motivation theory once they finish their university studies. Therefore, integrating motivation theory more into both preservice and practicing teacher training appears to be important.
\end{abstract}

Keywords Motivation - Self-determination theory · Expectancy-value theory · Attribution theory · Teacher training

Linda Schürmann

lschuerm@uni-koblenz.de

1 Institute of Psychology, University of Koblenz-Landau, Koblenz, Germany

2 Faculty of Psychology, FernUniversität in Hagen, Hagen, Germany 


\section{Introduction}

Motivation can broadly be described as what gets people to do what they do. It is a topic of relevance in the school context (Kunina-Habenicht et al. 2012) because processes underlying the initiation and maintenance as well as the quality of people's actions (Kaplan et al. 2012) are crucial for learning and achievement. Motivation "involves the internal processes that give behavior its energy and direction. (...) [T]hese internal processes energize behavior in multiple ways such as starting, sustaining, intensifying, focusing, and stopping it" (Reeve 1996, p. 2). It is therefore a crucial factor for successful learning, academic achievement, and persistence in school (Klauer and Leutner 2007; Pintrich 2003).

There is a rich body of work on the nature of motivation and its impact on both social and academic functioning. There are two important perspectives to consider when researching motivation in the school context. First, the student perspective. Motivation contributes to academic achievement because it influences when, what, and how things are learned (Schunk et al. 2014). It has an impact on learning even when cognitive skills are statistically controlled for (Steinmayr and Spinath 2009; Wigfield and Wentzel 2007). Motivation regarding school generally declines across the school years (Wigfield et al. 2007), which underlines the importance of the topic. Students who are not motivated to learn might not live up to their potentials in academic achievement. Additionally, not only the quantity but also the quality of students' motivation is an important factor for academic achievement (Ryan and Deci 2017). For example, more self-regulated, autonomous motivation is associated with better school outcomes (Guay et al. 2008). However, the impact of motivation on learning and achievement is highly complex. For instance, Tas (2016) explains that motivational factors have differential predictive effects on engagement, which again increases learning and achievement in school (Fredricks et al. 2016). Another example of the complex impact of motivation is that in German university students, even the recollection of their own motivation in the context of English as a subject during secondary school influenced their willingness to learn and participate in English education at university (Gorges et al. 2013).

Second, there is the teacher's perspective. Student motivation as a learned cognitive behavior (Schunk et al. 2014) can be influenced by the learning environment, which comprises the teacher, in both positive and negative ways (Wigfield and Wentzel 2007). Teachers "offer the general framework for the motivational beliefs of students" (Taheri 2011, p. 73). For example, reward and punishment is a topic of importance and has been discussed in detail within the framework of self-determination theory (e.g., Deci et al. 1999). This underlines the necessity for teachers to know and be able to utilize motivation theory in educational practice. However, many teachers appear unable to raise and maintain their students' motivation (Reeve 2009), which is in line with findings on the overall decreasing motivation throughout students' school careers (see above). To sum up, motivation has complex effects on learning and achievement. Therefore, knowledge about motivation theory is a prerequisite that practicing teachers should have and put into action.

This study aims to investigate the importance of motivation theory in teacher training. To offer a more complete view of the topic, we took a multidirectional view and included comparisons between assessments of preservice teachers who participated or did not participate in motivation theory seminars, and between preservice and practicing teachers. 


\section{Theoretical framework}

There are multiple theories with different underlying scopes and concepts about the nature of motivation and its connection to learning and achievement. Among these theories are selfdetermination theory, expectancy-value theory, and attribution theory (Kaplan et al. 2012; Syring 2018). Those theories are well-researched within the education context (e.g., Raufelder 2018). One key aspect they share in contrast to other motivation theories (cf. Weiner 1992) is that they grant a causal role to the subjective perspective of the person: How the student sees (1) roots of behavior, (2) chances of reaching a potential goal, and (3) causes of past success or failure is assumed to determine direction and intensity of future efforts. Due to their distinct relevance in the school context, they are in focus in the present paper.

Self-determination theory Self-determination theory (Ryan and Deci 2017; Ryan and Deci 2020) is an organismic theory of human behavior and personality development. It focuses on peoples' basic psychological needs for autonomy, competence, and social relatedness, which foster personal and social growth. The fulfillment of these needs is connected to the perception of self-determination (Deci and Ryan 1985; Ryan and Deci 2000). Self-determination theory takes seriously what people see as the source of their actions. Accordingly, intrinsic vs. extrinsic motivation are distinguished. Intrinsic motivation means that the person regards behavior as being performed for the sake of itself and that the behavior is in line with the abovementioned basic needs, while extrinsic motivation refers to behavior that is seen as externally controlled and tied to reaching some end. Rather than dichotomizing between intrinsic and extrinsic motivation, self-determination theory subdivides motivation into qualitatively different types of behavior regulation, which stand on a continuum from autonomous to controlled regulation of behavior. External behavior regulation is at the controlled end of the continuum, where motivation comes from external pressures, while intrinsically motivated behavior is the prototype of self-regulated motivation. Self-regulated motivation, such as intrinsic or integrated (extrinsic) behavior regulation, is most beneficial for learning. It is supported by the fulfillment of the basic psychological needs. However, schools are often rather controlling instead of need-supportive (Ryan and Deci 2017). Consequently, teachers are crucial when it comes to the support of self-regulated forms of motivation, through both the creation of autonomy-supportive learning contexts and their own motivational orientation as part of their professional competence (Brandenberger et al. 2018; de Naeghel et al. 2016; Ryan and Deci 2020). Self-determination theory is a vital topic in teacher training. It was chosen for this study because it highlights that teachers are crucial in creating an environment that supports self-regulated motivation in students.

Expectancy-value theory Expectancy-value theories focus on achievement motivation (e.g., Eccles and Wigfield 2002) and are therefore specifically useful in the school context, which usually focuses on achievement. Expectancy-value theories have produced some of the bestknown findings in motivational research (Wigfield et al. 2009). Generally, expectancy-value theories explain motivation as emerging from subjective expectancies that a certain behavior will entail certain consequences and by subjective or objective values of the consequences of said behavior (Raufelder 2018). Atkinson's (1957) risk choice model was the basis for other expectancy-value theories. It differentiates between the motivation to succeed and the motivation to avoid failure and connects them with emotions such as shame and pride. According to the model, people who strive for success tend to choose tasks of medium difficulty and take 
more difficult tasks when they succeed. Eccles and her colleagues (e.g., Eccles 1984; Eccles et al. 1983; Eccles and Wigfield 2002) integrated Atkinson's (1957) ideas into their complex model on achievement motivation. Achievement-related choices and performance are dependent on expectations of success and on the respective subjective task values, which are again determined by various factors such as goals or subjective perceptions. Expectancy-value theory was chosen for this study because teachers work with students with various individual expectancies and values while at the same time influencing student expectancies and values with their own behavior, which eventually has an impact on student motivation and therefore to some extent on student achievement.

Attribution theory Attribution theory (e.g., Weiner 1985, 1992) has remained influential in the field of motivation for more than 30 years (Weiner 2018). Attribution theory deals with subjective reasons for failure or success and can therefore be regarded as a complement to Atkinson's theory (Raufelder 2018). There are three causal dimensions along which attributions are made: locus of control, stability, and controllability (Weiner 1992; Weiner et al. 1971). People differ in their general attribution style, which leads to different affective reactions to the same situations. Teachers can support beneficial motivational patterns by giving adequate attributional feedback (Dresel 2004). Attributional biases are also prevalent at school (Schunk et al. 2014). The fundamental attribution error (Ross 1977), for instance, is the tendency of people to overemphasize an agent's disposition, e.g., internal factors, when explaining his or her behavior. Teachers should know about common biases to optimize their students' learning possibilities by treating them fairly. Attribution theory was chosen for this study because attributions are most often made in situations in which something did not go as desired or expected (Schunk et al. 2014). Therefore, they are of relevance in the school context, where students are evaluated regularly, for instance by teacher feedback or grades.

Self-determination theory, expectancy-value theory, and attribution theory share important aspects. For example, attribution theory and expectancy-value theory are closely linked because they both consider reactions to failures and people's general attribution style as influencing future (learning) behavior through expectation and value. The modern expectancy-value theory includes children's interpretations of experiences and their affective reactions and memories (Eccles and Wigfield 2002). Self-determination theory as well as attribution theory deals with the locus of control and controllability, and expectancy-value integrates aspects of self-determination theory through the intrinsic value and the attainment value of a task. Therefore, we chose these theories because they help to get a useful, wellresearched, complex, and practical picture of motivation as a multidimensional construct in the school context.

Motivation theory and teacher education The teacher's influence on student motivation and the importance of student motivation for learning underlines the significance of learning and teaching motivation theory to future teachers at university. Hence, the topic motivation is comprised in larger frameworks such as COACTIV (Professional Competence of Teachers, Cognitively Activating Instruction, and Development of Students' Mathematical Literacy, Kunter 2011; Kunter et al. 2011; Voss and Kunter 2011) or TEDS (Teacher Education and Development Study, Blömeke et al. 2011, 2010) which deal with teachers' professional competence and cover motivation among other aspects. Knowledge about motivation theory can be considered a cognitive component of professional teaching competence. Professional teaching competence is a part of teachers' pedagogical knowledge (cf. Baumert and Kunter 
2006; Blömeke et al. 2011; Blömeke et al. 2010; König 2010). There has been extensive research on pedagogical knowledge and its assessment (see, e.g., Voss et al. 2015, for an overview). COACTIV regards the topic motivation as part of teachers' pedagogicalpsychological knowledge, i.e., knowledge about motivational aspects of learning, and causal attributions (Voss and Kunter 2011). TEDS-M comprises intrinsic and extrinsic motivation, basic principles of achievement motivation, and motivation strategies (Blömeke et al. 2010). However, motivation is of such importance in the school context and therefore in teacher training that it deserves a more detailed view. To our knowledge, large studies such as COACTIV or TEDS-M have not covered all of the abovementioned motivation theories but rather focused on one of them next to a variety of other aspects. Hence, we targeted selfdetermination theory, expectancy-value theory, and attribution theory to add to a more complete view.

In Germany, regular public teacher training is separated into phases. First, preservice teachers study at university. At the university in focus, the study program is divided into the content subjects and education sciences. Preservice teachers choose at least two subjects as content subjects, for instance, Mathematics and Biology. Additionally, all preservice teachers study education sciences. The education sciences program consists of different modules with seminars and lectures. Generally, students have to complete three modules for their bachelor's degree and one for their master's degree. ${ }^{1}$ Second, the student teachers go through a preparatory service, which is more practical. They teach at school and complete the preparatory service with the second state examination, which enables them to teach at public schools and become a civil servant.

Rationale and purpose of the study Motivation theory is mentioned as a topic in the German education sciences curriculum for teacher training at university. Thus, preservice teachers should learn about motivation theory during the first phase of their training (Standing Conference of Education and Cultural Affairs 2019). Therefore, knowledge about motivation theory is assumed when preservice teachers start their preparatory service. However, there is no strict guideline on how and where to integrate motivation theory into the education sciences program.

In other contexts, e.g., intellectual giftedness (e.g., Heyder et al. 2018), it has been found that some topics are not sufficiently treated in teacher education and need to be addressed more to ensure an adequate level of knowledge. Motivation might be another example of the current debate on a lack of connection between the different phases of teacher training (link between theory and practice, see, e.g., Vogel 2011). If preservice teachers do not learn about motivation theory during their studies (theory), they are not adequately prepared for this requirement (Standing Conference of the Ministers of Education and Cultural Affairs 2019) when they start their preparatory service (practice).

Therefore, we investigated motivation theory as an aspect of teachers' professional knowledge. We considered the perceived relevance of the topic because teachers who believe that motivation theory is relevant for their jobs might be more ready to put what they learn into action (see, e.g., Ryan and Deci 2017). We considered their perceived experience with the topic because there is no curriculum stating where and how to teach motivation theory at university. It was therefore of interest how teachers experience their

\footnotetext{
${ }^{1}$ Slightly different regulations apply for elementary school teaching students, who focus on "elementary school education" after their fourth study semester.
} 
points of contact with motivation theory. We considered their perceived knowledge about motivation theory because the self-concept of ability is closely linked to learning motivation and therefore to achievement (Gorges et al. 2013). We considered their actual knowledge to gauge what (preservice) teachers actually know about the three theories in question.

We hypothesized that among the preservice teachers, more experience in education sciences in general is connected to more perceived (1) experience with the topic "motivation theory in the school context" and (2) knowledge about the topic as well as to the assignment of (3) more relevance to the topic. Moreover, we hypothesized that (4) more experience in education sciences in general was connected to more actual knowledge about motivation theory in preservice teachers.

We included (perceived and actual) knowledge as variables because motivation is a construct that is used in everyday language and part of the set of personal beliefs about learning and teaching that preservice teachers hold when entering their teacher program. These beliefs might be difficult to change (Joram and Anthony 1998).

Furthermore, we hypothesized that (5) preservice and practicing teachers displayed differences in their experience with and (perceived) knowledge about the topic "motivation theory in the school context" as well as in the relevance they assigned to it. We were interested in a comparison between preservice and practicing teachers because of the ongoing discussion about the link between theory and practice in teacher training (e.g., Vogel 2011), which might also hold true for the aspect of motivation theory.

Taken together, the study had two objectives: FIRST, to investigate whether experience in education sciences was related to preservice teachers' attitudes and knowledge concerning motivation theory in the school context. Experience in education sciences was operationalized as the number of completed modules in education sciences and participation in a motivation theory seminar. Attitudes and knowledge were operationalized as perceived experience with motivation as a school-related topic, perceived and actual knowledge about it, and the perception of its relevance in the school context. The second objective was to describe whether there were differences between the results of preservice teachers and those of practicing teachers. We calculated regression models for the first objective and analyses of variance for the second objective.

\section{Material and method}

\section{Participants}

Of the $N=322$ participants, $n=269$ were preservice teachers from a German university and $n=53$ were practicing teachers in Germany. Of the preservice teachers, $n=29$ had already visited a motivation theory seminar during their education sciences studies. Participants were aged between 18 and 63 years (overall $M=25.74, S D=7.82$, preservice teachers $M=23.17, S D=3.33$, practicing teachers $M=38.70, S D=$ 10.63), $75.5 \%$ were women, $21.4 \%$ were men, and $3.1 \%$ indicated "other." Practicing teachers were between their first and 35th year of practice $(M=11.20, S D=9.9)$, came from various federal states in Germany, mostly worked at grammar schools $(35 \%)$ or elementary schools $(32.5 \%)$, and taught various subjects. 


\section{Data collection}

The motivation theory seminars were held in the summer and winter term in 2017. Preservice teachers participated in a 15-min paper-pencil-questionnaire on a voluntary basis. The preservice teachers with a motivation seminar background answered the questionnaire at the end of the last day of the seminar, and all other preservice teachers answered the questionnaire at the end of their respective seminar that did not deal with motivation theory. We checked whether they had already visited another motivation theory seminar in the questionnaire. We recruited practicing teachers through an online teacher forum. They accessed the same questionnaire voluntarily as an online version.

The first part of the questionnaire focused on participants' opinions towards the three motivation theories (self-determination theory, expectancy-value theory, and attribution theory) in the school context. We asked for their perceived experience with the topic, its relevance, and their perceived knowledge about it. The three variables were calculated as the mean score of three scales: perceived experience, perceived relevance, and perceived knowledge. The scales comprised two items for each of the three theories in focus, i.e., six items per scale. They stated basic terms connected to each theory, namely "motivation to approach success ('hope for success')" and "motivation to avoid failure ('fear of failure')" for expectancy-value theory, "internal/external attributions" and "locus, stability, and controllability of behavior" for attribution theory, and "intrinsically/extrinsically motivated behavior" and "integrated/identified/ introjected behavior" for self-determination theory. We chose to include only two items per theory to keep the questionnaire as short as possible. The items were created by using the main terms connected to each theory.

Participants scored their subjective opinion using a 7-point rating scale (0 to 6) for each item. Regarding the scale for perceived relevance, we added an answer option "I cannot assess this" in case the participants did not feel able to evaluate the relevance, see Table 1 for all items. The two independent variables indicating experience regarding motivation theory were the number of completed modules in education sciences and the visit of a seminar directly dealing with the topic motivation ("motivation theory seminar"). The number of completed modules in education sciences was chosen as an indicator of a later stage of education because motivation theory should be covered during the Bachelor of Education programs in Germany according to the curriculum of education sciences (Standing Conference of Education and Cultural Affairs 2019). Students can choose from different seminars in each module so that not every student necessarily covers motivation $\mathrm{n}$ theory during their studies. Finally, all participants could add a comment. These qualitative data were used to clarify quantitative data if needed.

The second part of the questionnaire consisted of six single-choice questions on the motivation theories to test participants' actual knowledge about them. Each theory was represented by two questions (see Table 2 for the questions, answer options, and item difficulties). The test appeared to be difficult; the guessing-corrected item difficulties lay between -0.061 (item 5) and 0.264 (item 4), see Table 2. The negative value indicates that one wrong answer option had been marked more often than the correct one. The overall reliability of the knowledge test was Cronbach's $\alpha=0.735$.

\section{Data analysis}

We calculated the mean scores of the three scales "perceived experience," "perceived relevance," and "perceived knowledge," as reliability was given; see Table 1. For the knowledge 
Table 1 Items and reliabilities of the scales "perceived experience", "perceived relevance," "perceived knowledge," and "actual knowledge" (regarding motivation as a school-related topic) for preservice teachers

\begin{tabular}{|c|c|c|c|}
\hline & \multicolumn{3}{|l|}{ Scale: perceived... } \\
\hline & Experience & Relevance & Knowledge \\
\hline Task & $\begin{array}{l}\text { Please indicate how } \\
\text { intensively you have } \\
\text { dealt with the following } \\
\text { topics within the } \\
\text { framework of education } \\
\text { sciences }\end{array}$ & $\begin{array}{l}\text { Please indicate how } \\
\text { relevant you find the } \\
\text { following topics within } \\
\text { the framework of } \\
\text { education sciences }\end{array}$ & $\begin{array}{l}\text { Please indicate } \\
\text { how much you } \\
\text { think you know } \\
\text { about the } \\
\text { following topics }\end{array}$ \\
\hline $\begin{array}{l}\text { Reliability: Cronbach's } \alpha \\
\text { Item } M(S D)\end{array}$ & 0.962 & 0.935 & 0.912 \\
\hline $\begin{array}{l}\text { Expectancy-value theory (e.g., } \\
\text { Atkinson's model on } \\
\text { risk-taking behavior) }\end{array}$ & $0.46(1.02)$ & $2.99(1.46)$ & $0.65(1.25)$ \\
\hline $\begin{array}{l}\text { Attributional theory of } \\
\text { motivation (e.g., Weiner) }\end{array}$ & $0.53(1.18)$ & $3.34(1.44)$ & $0.72(1.33)$ \\
\hline $\begin{array}{l}\text { Self-determination theory (e.g., } \\
\text { Deci and Ryan) }\end{array}$ & $0.55(1.13)$ & $3.83(1.49)$ & $0.33(0.98)$ \\
\hline $\begin{array}{l}\text { Motivation to approach success } \\
\text { ("hope for success") }\end{array}$ & $0.83(1.20)$ & $4.30(1.32)$ & $1.34(1.62)$ \\
\hline $\begin{array}{l}\text { Motivation to avoid failure } \\
\text { ("fear of failure") }\end{array}$ & $1.15(1.49)$ & $4.55(1.32)$ & $1.47(1.68)$ \\
\hline Internal/external attributions & $0.93(1.47)$ & $4.12(1.32)$ & $1.17(1.57)$ \\
\hline $\begin{array}{l}\text { Locus, stability, and } \\
\text { controllability of behavior }\end{array}$ & $0.90(1.40)$ & $4.15(1.48)$ & $0.98(1.44)$ \\
\hline $\begin{array}{l}\text { Intrinsically/extrinsically } \\
\text { motivated behavior }\end{array}$ & $2.18(2.00)$ & $4.29(1.40)$ & $2.01(1.94)$ \\
\hline $\begin{array}{l}\text { Integrated/identified/introjected } \\
\text { motivated behavior }\end{array}$ & $0.85(1.41)$ & $4.25(1.45)$ & $0.83(1.38)$ \\
\hline $\begin{array}{l}\text { Scale } \\
M(S D)\end{array}$ & $0.95(1.01)$ & $4.15(1.17)$ & $1.06(1.15)$ \\
\hline$N$ & 264 & 231 & 265 \\
\hline
\end{tabular}

Ann. $M=$ mean. $S D=$ standard deviation

test, we calculated a sum score of all items with a possible maximum of 6 and a possible minimum of 0 correctly solved items. When there was no answer given, the item was coded as answered incorrectly. Varying sample sizes occurred when only one group was regarded (e.g., only preservice teachers, as in Table 3) or when values were missing, e.g., when participants did not answer all items.

After we calculated the mean values and sum scores, we tested hypotheses 1, 2, 3, and 4; i.e., we tested whether the number of completed modules in education sciences and the visit of a motivation theory seminar were related to the mean values of the scales perceived experience, perceived relevance, and perceived and actual knowledge for the preservice teacher sample. We excluded outliers of more than three standard deviations and calculated linear regression analyses after checking the requirements (normality of residuals, linearity, heteroscedasticity, multicollinearity, Field 2013) with the two independent variables (number of completed modules in education sciences and visit of seminar about motivation) as factors for each of the dependent variables (i.e., perceived experience, perceived relevance, perceived knowledge, and actual knowledge). In a second step, we added the data of the practicing teachers and compared their results to those of the preservice teachers. We explored the 
Table 2 Knowledge items, answer options including correct answers, theoretical basis, and guessing-corrected item difficulty of preservice and practicing teachers

\begin{tabular}{lll}
\hline Item & $\begin{array}{l}\text { Answer options (\% of answers, italics } \\
\text { mark correct answer) }\end{array}$ & $\begin{array}{l}\text { Theory } \\
\text { Item } \\
\text { difficulty }\end{array}$ \\
\hline
\end{tabular}

Which task difficulty do people with a high expectancy for success prefer?
1.Very easy and very difficult tasks (12.6\%)

2.Tasks of medium difficulty (29.0\%)

3.Difficult tasks (17.6\%)

4.Easy tasks $(11.5 \%)$

5.Task difficulty is not important, they focus on response speed $(12.6 \%)$

6.No indicated answer (16.8\%)

If a teacher attributes the bad grade of a pupil to 1. Receptive fallacy (13.1\%) his laziness, but actually, the student just slept 2 .Teacher-student fallacy $(9.6 \%)$ this is called...

\section{According to Deci and Ryan's (1985)}

Self-Determination Theory, there are three basic psychological needs. These are the need for...

3.Deficiency hypothesis paradoxon (4.6\%) 5.Actor-observer bias (25.0\%)

6.No indicated answer $(23.5 \%)$

1.Intrinsic motivation, competence, autonomy $(6.1 \%)$

2.Intrinsic motivation, extrinsic motivation, autonomy $(13.4 \%)$ very badly during the night before the test,

In a ring toss game, Jan has to throw rings from different distances. He can choose the distance from which he throws the ring. He gets more points for larger distances. He chooses a medium distance and enlarges it because he always aims correctly. Which conclusion can you draw from the point of view of the risk choice model?

Tom gets back his math test. He has paid attention during math class and has always done his homework. But he only passed with a "D". He says: "Oh well, math is a difficult subject, this is not my fault. Maybe next time I'll have more luck with the test." What can you say about his attributions (causal dimensions)?

Katja enjoys writing papers. Lately, she has gotten a reward for each good grade in her favorite subject, German, by her parents, no matter whether she has studied a lot or not at all for the tests. Which consequences might this have according to the results of motivation psychology? Katja's...
3.Motivation is not influenced by the rewards $(2.3 \%)$

4.Intrinsic and extrinsic motivation increase $(17.2 \%)$

5.Intrinsic motivation decreases (35.9\%)
4.Regressive assessment fallacy $(24.2 \%)$

3.Competence, autonomy, social relatedness $(27.1 \%)$

4.Extrinsic motivation, social relatedness, competence $(10.3 \%)$

5.Autonomy, social relatedness, intrinsic motivation $(17.9 \%)$

6.No indicated answer $(25.2 \%)$

EVT 0.144

1.High subjective expectancy for success (36.5\%)

2.There is no correlation between Jan's throwing distance and his expectancy for success $(6.5 \%)$

3.His achievement level stays the same (4.6\%)

4.He has a low subjective expectancy for success $(13.5 \%)$

5.His expectancy for success does not correlate with his achievement level (18.8\%)

6.No indicated answer $(20.0 \%)$

1.Internal, stable, controllable $(10.4 \%)$

2.External, unstable, uncontrollable (29.2\%)

3.Internal, stable, uncontrollable (19.6\%)

4.External, unstable, controllable $(11.2 \%)$

5.External, stable, controllable $(5.4 \%)$

6.No indicated answer $(24.2 \%)$

1.Intrinsic motivation increases $(11.1 \%)$ 
Table 2 (continued)

\begin{tabular}{lll}
\hline Item & $\begin{array}{l}\text { Answer options (\% of answers, italics } \\
\text { mark correct answer) }\end{array}$ & $\begin{array}{l}\text { Theory } \\
\text { Item } \\
\text { difficulty }\end{array}$ \\
\hline
\end{tabular}

6.No indicated answer $(20.2 \%)$

Ann. $E V T=$ expectancy-value theory. $S D T=$ self-determination theory. $A T=$ attribution theory

question whether there were differences in preservice and practicing teachers' levels of perceived experience, perceived relevance, perceived knowledge, and actual knowledge with Univariate Analyses of Variance, including post hoc Bonferroni (perceived experience and perceived relevance) and Games-Howell tests (in case of violation of variance homogeneity, held true for perceived and actual knowledge). We differentiated preservice teachers with and without a motivation theory seminar background and practicing teachers. None of the practicing teachers had visited a motivation theory seminar.

\section{Results}

\section{Preservice teachers' perceived experience with motivation theory, its relevance, and knowledge about it in the school context}

All regression models were significant, $p<0.05$. The models, which included the number of completed modules in education sciences and the visit of a motivation theory seminar, had a high goodness of fit for the values for perceived experience and actual and perceived knowledge about motivation theory in the school context (highest $R^{2}$ adjusted $=0.578$ for

Table 3 Linear regression analyses for perceived experience, perceived relevance, perceived knowledge, and the knowledge test score for preservice teachers

\begin{tabular}{|c|c|c|c|c|c|}
\hline & $M(S D)$ & $B(S D)$ & $\beta$ & $T$ & $p$ \\
\hline \multicolumn{6}{|l|}{ Perceived experience } \\
\hline$N=261, M=1.27, S D=1.40, R^{2}$ adjusted $=0.578$, & & & & & $<0.001$ \\
\hline Motivation theory seminar & $0.09(0.29)$ & $3.57(0.20)$ & 0.740 & 18.32 & $<0.001$ \\
\hline Completed modules & $2.00(1.53)$ & $0.21(0.04)$ & 0.227 & 5.62 & $<0.001$ \\
\hline \multicolumn{6}{|l|}{ Perceived relevance } \\
\hline$N=231, M=4.41, S D=0.95$ & & & & & 0.002 \\
\hline \multicolumn{6}{|l|}{$R_{\text {adjusted }}^{2}=0.025$} \\
\hline Motivation theory seminar & $0.18(0.31)$ & $0.45(0.20)$ & 0.148 & 2.26 & 0.025 \\
\hline Completed modules & $2.12(1.49)$ & $0.08(0.04)$ & 0.121 & 1.84 & 0.066 \\
\hline \multicolumn{6}{|l|}{ Perceived knowledge } \\
\hline $\begin{array}{l}N=265, M=1.21, S D=1.34 \\
R^{2} \text { adjusted }=0.531\end{array}$ & & & & & $<0.001$ \\
\hline Motivation theory seminar & $0.10(0.30)$ & $3.18(0.19)$ & 0.703 & 16.49 & $<0.001$ \\
\hline Completed modules & $2.03(1.52)$ & $0.22(0.04)$ & 0.252 & 5.91 & $<0.001$ \\
\hline \multicolumn{6}{|l|}{ Actual knowledge (knowledge test score) } \\
\hline \multicolumn{6}{|l|}{$R_{\text {adjusted }}^{2}=0.320$} \\
\hline Motivation theory seminar & $0.10(0.29)$ & $2.90(0.26)$ & 0.566 & 11.09 & $<0.001$ \\
\hline Completed modules & $1.98(1.53)$ & $0.10(0.05)$ & 0.103 & 2.022 & $<0.044$ \\
\hline
\end{tabular}


perceived experience, lowest $R^{2}$ adjusted $=0.320$ for perceived knowledge, see Table 3) and a low goodness of fit for perceived relevance $\left(R^{2}\right.$ adjusted $=0.025$, see Table 3) (Cohen 1988).

Preservice teachers' perceived experience with the topic was low $(M=1.27, S D=1.40$ on a scale from 0 to 6 ). While preservice teachers who had visited a motivation theory seminar perceived themselves as rather experienced with the topic, $M=4.28, S D=1.41$, preservice teachers without a motivation theory seminar background indicated to have almost no experience with it, $M=0.98, S D=0.99$. The attendance of a motivation theory seminar and the number of completed modules in education sciences were significantly connected to the mean perceived experience level, especially the motivation theory seminar $(\beta=0.74)$. This supports hypothesis 1 .

Preservice teachers regarded motivation as a topic of relevance in the school context. The mean perceived relevance was at a medium to medium-high level $(M=4.41, S D=0.95)$, which shows that preservice teachers tend to find it relevant in the context of their future work. Whether preservice teachers had visited a seminar specifically dealing with motivation theory or not was significantly related to their perception of the topic's relevance, but not the number of completed modules in education sciences. The adjusted $R^{2}$ of the model was, however, small $\left(R^{2}\right.$ adjusted $\left.=0.025\right)$.

Preservice teachers' perceived knowledge about motivation theory was rather low $(M=$ $1.21, S D=1.34$ ), and both the visit of a motivation theory seminar and the number of completed modules in education sciences were significantly related to it, especially the visit of a seminar dealing with motivation theory $(\beta=0.74)$.

In the knowledge test, on average, only about two out of six items were solved correctly. Actual knowledge was therefore rather low and again predicted by both independent variables, especially the visit of a seminar on motivation theory; see Table 3 for details for all regression models. Overall, we found that experience in education sciences in general predicted perceived experience, perceived relevance, perceived knowledge, and actual knowledge. Yet, although the topic is considered relevant by preservice teachers, they indicate lower levels of experience with it and knowledge about it. This is backed up by the sum score in the short knowledge test.

Regarding the perceived relevance of motivation as a school-related topic, there is another important point to mention. The scale perceived relevance also consisted of nine items but had one more answer option, "I cannot assess this." This answer option was chosen between $31.7 \%$ (item 8) and $70.6 \%$ (item 1) times.

\section{Comparison of preservice and practicing teachers}

Comparing the three groups $(N=29$ preservice teachers with a motivation seminar background, $N=269$ without a motivation seminar background, and $N=53$ practicing teachers), we found that there were significant differences between the groups for each of the four dependent variables perceived experience, $F(2,314)=109.616, p<0.001, \mu_{\mathrm{p}}{ }^{2}=0.411$; perceived relevance, $F(2,270)=55.352, p<0.001, \mu_{\mathrm{p}}{ }^{2}=0.291$; perceived knowledge, $F(2,51.571)=102.039, p<.001, \mu_{\mathrm{p}}{ }^{2}=0.342$; and actual knowledge, $F(2,42.240)=$ $129.530, p<0.001, \mu_{\mathrm{p}}{ }^{2}=0.316$; see Fig. 1 . Preservice teachers with a motivation theory seminar background displayed the highest mean values for all variables, with medium to medium-high values, while preservice teachers without a motivation theory seminar background displayed rather low values except for the perceived relevance of motivation in schoolrelated contexts. Practicing teachers reported to have little experience with and knowledge about the topic but scored higher than preservice teachers regarding their actual knowledge about it. Practicing teachers assigned less relevance to the topic than preservice teachers without a specific background in motivation theory; see Fig. 1. 


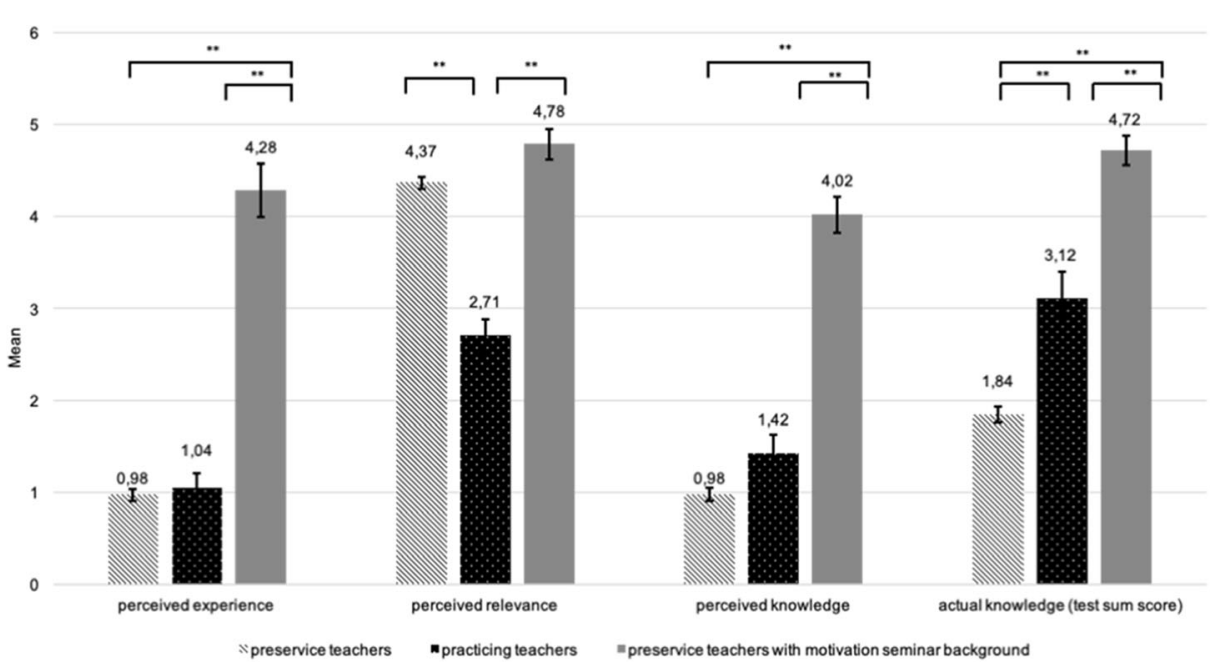

Fig. 1 Mean values of preservice teachers with and without a motivation seminar background and practicing teachers for perceived experience, perceived relevance, perceived knowledge, and test sum score. Note that error bars indicate standard deviations. $* * p<0.001$

\section{Discussion}

We investigated the perceived relevance of knowledge and actual knowledge of preservice teachers concerning motivation theory and explored differences between preservice and practicing teachers.

\section{Preservice teachers' self-reports}

Overall, all preservice teachers' self-reports showed that they believe to have almost no to only a little knowledge about motivation theory. Apparently, preservice teachers do not have the feeling that motivation theory makes for a big part in their studies in education sciences. This is an important finding: The topic motivation does not seem to be strongly and explicitly represented within the education actually taught sciences curriculum, although it is required as a competence of teachers (Standing Conference of Education and Cultural Affairs 2019). This corresponds with their lack of knowledge: Preservice teachers on average answered hardly more than 2 of 6 questions on the three motivation theories in focus. Contrasts to other findings (see, e.g., König et al. 2011) might be explained by differences in the distinct aspects of motivation theory that were tested. While in the TEDS study participants could answer most items on motivation (72-87\% solution frequency), we found a correspondence of lack of knowledge and low perceived knowledge.

Regarding actual knowledge, preservice teachers who had already visited a seminar on motivation theory were strikingly different from all other participants: The visit of a seminar on motivation theory had the strongest influence on all variables (perceived relevance of the topic, perceived experience with it, and perceived and actual knowledge about it). Linear regression analyses showed that experience in education sciences explained variance in these variables. Perceived experience with motivation as a school-related topic was significantly connected to both the visit of the motivation theory seminar and the general experience in education sciences. The same counted for the perceived and actual knowledge about the topic. Accordingly, there appears to be a need for more contact of preservice teachers with the topic motivation, which is in line with findings in the 
domain of giftedness by Heyder et al. (2018). The authors found that intellectual giftedness needs to be addressed more during teacher training to ensure an adequate level of knowledge about the topic. In this matter, the duration of the seminar could be of further interest. The participants attended the motivation theory seminar for only one semester. Another option would be to study motivation not only in education sciences but also in the subject didactics from subject-specific perspectives.

To sum up, we found that there appears to be a positive connection between experience in education sciences in general and a (perceived) positive opinion and knowledge of preservice teachers regarding motivation theory in the school context. This is in line with the requirements by the Standing Conference of the Ministers of Education and Cultural Affairs (2019), although preservice teachers without a motivation theory seminar background display a rather cautious perception of their own experience with the topic and knowledge about it. Thus, more training in motivation theory would be useful for preservice teachers to live up to the requirements set by the Standing Conference of Education and Cultural Affairs (2019). This is again underlined by the distinct connection of the visit of the motivation theory seminar to higher mean values in all selfreports and the actual sum score in the short knowledge test: Although it might appear trivial at first, the impact of the motivation theory seminar is an important and positive sign, because it shows that it is crucial but at the same time manageable to improve this competence in preservice teachers.

\section{Comparison of preservice and practicing teachers}

We furthermore compared preservice teachers with and without a motivation theory seminar background to practicing teachers as a contribution to the ongoing discussion about the link between the theoretical and the practical part of teacher training. According to Vogel (2011), there seems to be a transition problem between both phases of teacher training and we aimed at describing whether motivation theory might be an example illustrating this problem.

Regarding the perceived experience with the topic, we found that both preservice teachers without a motivation theory background and practicing teachers reported very little experience, unlike preservice students with a motivation theory seminar background. This might indicate that motivation theory is not a core topic in the advanced training of practicing teachers as well, or at least that practicing teachers do not perceive it as a core topic. The same answer pattern was found for perceived knowledge: Both preservice teachers without a motivation theory seminar background and practicing teachers did not believe to know much about motivation theory, unlike preservice teachers with a motivation theory seminar background. Interestingly, however, practicing teachers answered more questions concerning the three theories in focus correctly than preservice teachers without the seminar background. This might illustrate that they gather experience they can use to argue about motivation theory during their practicing years.

The answer patterns to the perceived relevance of the topic also add to the discussion on the connection between theory and practice in teacher training (see, e.g., van Buer and Petzold-Rudolph 2015; Vogel 2011): All preservice teachers assigned medium to medium-high values to the relevance of motivation theory in the school context. The subjective relevance of the topic is high and might be further increased by specific teaching. Notably, practicing teachers assigned significantly less relevance to the topic than preservice teachers. This might be one of the most interesting findings of the present study. Relevance is a positive indicator of intrinsic motivation in self-determination theory (Deci \& Ryan 2017) and the value-aspect in expectancy-value theory (Eccles 
and Wigfield 2002) and might, therefore, lead towards an actual usage of motivation theory in concrete situations through more perceived autonomy (Assor et al. 2002), but there might be a shift in the perceived relevance of motivation theory after teachers really start teaching at school. It might be worth investigating this shift in more detail. When practicing teachers do not assign much relevance to motivation theory anymore, it becomes less likely that they are intrinsically motivated to make use of such theories during teaching (Assor et al. 2002; Ryan and Deci 2017). There are numerous reasons why practicing teachers might think that motivation theory is not very useful in actual teaching: they might question the usability of theory in real-life situations in general, or motivation theory specifically, or they might not feel well-prepared but still succeed in their job and therefore presume uselessness of (motivation) theory for practice. We used the open commentary field and checked for answers of preservice and practicing teachers. Of all preservice teachers, $n=11$ added a comment. They mentioned that they had only heard very little of motivation theory in education sciences. They called for more input concerning motivation theory, but with an orientation towards practical examples. Five practicing teachers added a comment. The answers were as follows: "In my opinion, all these theories are platitudes, but expressed in such a complicated way ... ...more practice orientation in teacher training should replace these theories.", "31 years ago, these terms were (at least in Eastern Germany, [...], not at all known. I mainly guessed. [...]. I still became a good teacher who can cause interest, motivation, and exhilarating experiences of happiness in his students.", "Preparation? Zero. Although I would have liked it.", and "The only experiences I have regarding this topic are empirical values which I have experienced myself during teaching." Preservice and practicing teachers value practice orientation and practicing teachers might be more critical of theory in general (see, e.g., Haas 2005; Helsper 2002). When teachers start teaching at school, they might not see much usage in (motivation) theory (anymore) but rather work with what they learn "as they go." Training should target skills to apply theoretical knowledge during and after preparatory service. Another line of thought is that perception of relevance is compromised by the multi-faceted context of teaching. While preservice students might focus on motivation and see its relevance as obvious, the more complex actual teaching context might only allow for the usage of profoundly understood principles. As knowledge on the abovementioned theories has been proven to be useful in practice (see above), one could argue that the lack of perceived relevance in practicing teachers shows that motivation theory is taught too superficially during university and cannot be put into practice by those teachers. This adds to the ongoing discussion on the link between theory and practice in German teacher training (Vogel 2011; van Buer and Petzold-Rudolph 2015).

\section{Limitations}

There are limitations to this study. Instead of comprehensively testing motivation theories, we picked three prominent branches. Our selection was theoretically based, because the three theories are well-researched, closely connected to the field of education, and have brought forth important findings in the field of motivational psychology (see, e.g., Wentzel and Wigfield 2009). Yet, testing motivation knowledge based on a selection that is representative of what is actually taught at university would be a goal for future studies. Similarly, determining expert agreement on what should be covered seems fruitful (Howell et al. 2014; Peter et al. 2015). 
Preservice teachers' actual knowledge about motivation theory has been studied within much larger frameworks (e.g., COACTIV or TEDS, Blömeke et al. 2011, 2010; Kunter 2011; Voss and Kunter 2011). They have not focused on all of these theories but rather on very specific aspects such as intrinsic/extrinsic motivation or attribution. Regarding the differences between preservice and practicing teachers, a longitudinal study design would be useful. This cross-sectional study with different sample sizes of subgroups should be a useful basis for such a study.

Another limitation is that this study only focuses on knowledge and not on know-how. It is never enough for teachers to (only) know about a theory, but they have to be able to put it into action and apply it daily (see, e.g., Baumert and Kunter 2006). Due to the length of the questionnaire, we chose to include only six items to test the participants' actual knowledge about motivation theory, i.e., two items per theory. Further research might develop a more detailed test on knowledge about motivation theory to investigate various aspects of motivation theory in the school context in more detail.

\section{Conclusion}

The main finding of this study is that motivation as a school-related topic might not be dealt with sufficiently to ensure that student teachers can live up to the standards set by the Standing Conference of the Ministers of Education and Cultural Affairs (2019) in Germany. Moreover, this might impede the linkage of theory and practice between the first and second phase of teacher education, an aspect that is discussed in the German context to improve teacher education (Vogel 2011). These findings are interesting and novel, because, different from larger prior studies, we compared preservice and practicing teachers' perspectives and knowledge with regard to three motivation theories relevant in the school context in more detail.

Our findings are important for practice, especially for university education: A more intensive and explicit integration of the topic motivation into university education, for example by covering the topic in the respective subject didactics, as well, might improve preservice teachers' opinions and knowledge about this important aspect of teachers' professional competence. In the long run, teachers who are well-prepared to motivate their students in various contexts might contribute to the solution of problems such as the lack of motivation for Science, Technology, Engineering, and Mathematics (STEM) subjects, which displays the importance of our findings for practice.

Acknowledgements Open Access funding provided by Projekt DEAL.

Funding We thank the German Ministry for Education and Research for funding the project MoSAiK (Modulare Schulpraxiseinbindung als Ausgangspunkt zur individuellen Kompetenzentwicklung)—support code 01JA1605-in the framework of "Qualitätsoffensive Lehrerbildung."

Data availability The data that support the findings of this study are available from the corresponding author, LS, upon reasonable request.

\section{Compliance with ethical standards}

Conflict of interest The authors declare that they have no conflict of interest. 
Code availability Application software SPSS Statistics

Open Access This article is licensed under a Creative Commons Attribution 4.0 International License, which permits use, sharing, adaptation, distribution and reproduction in any medium or format, as long as you give appropriate credit to the original author(s) and the source, provide a link to the Creative Commons licence, and indicate if changes were made. The images or other third party material in this article are included in the article's Creative Commons licence, unless indicated otherwise in a credit line to the material. If material is not included in the article's Creative Commons licence and your intended use is not permitted by statutory regulation or exceeds the permitted use, you will need to obtain permission directly from the copyright holder. To view a copy of this licence, visit http://creativecommons.org/licenses/by/4.0/.

\section{References}

Assor, A., Kaplan, H., \& Roth, G. (2002). Choice is good, but relevance is excellent: autonomy-enhancing and suppressing teacher behaviours predicting students' engagement in schoolwork. British Journal of Educational Psychology, 72, 261-278.

Atkinson, J. W. (1957). Motivational determinants of risk-taking behavior. Psychological Review, 64(6), 359-372.

Baumert, J., \& Kunter, M. (2006). Stichwort: Professionelle Kompetenz von Lehrkräften. (Keyword: Professional competence of teachers). Zeitschrift für Erziehungswissenschaft, 9(4), 469-520.

Blömeke, S., Kaiser, G., \& Lehmann, R. (2010). TEDS-M 2008 - Professionelle Kompetenz und Lerngelegenheiten angehender Mathematiklehrkräfte im internationalen Vergleich. (Professional competence and learning opportunities of preservice mathematics teachers in international comparison). Münster: Waxmann.

Blömeke, S., Bremerich-Vos, A., Haudeck, H., Kaiser, G., Nold, G., Schwippert, K., \& Willenberg, H.. (2011). Kompetenzen von Lehramtsstudierenden in gering strukturierten Domänen: Erste Ergebnisse aus TEDS-LT. (Competences of preservice teachers in low-structured environments: first results of TEDS-LT.) Münster: Waxmann.

Brandenberger, C. C., Hagenauer, G., \& Hascher, T. (2018). Promoting students' self-determined motivation in maths: results of a 1-year classroom intervention. European Journal of Psychology of Education, 33(2), 295-317.

Cohen, J. (1988). Statistical power analysis for the behavioral sciences (2nd ed.). Hillsdale, NJ: Lawrence Erlbaum.

De Naeghel, J., van Keer, H., Vansteenkiste, M., Haerens, L., \& Aelterman, N. (2016). Promoting elementary school students' autonomous reading motivation: effects of a teacher professional development workshop. Journal of Educational Research, 109(3), 232-252.

Deci, E. L., \& Ryan, R. M. (1985). Intrinsic motivation and self-determination in human behavior. New York: Springer Science and Business Media, LLC..

Deci, E. L., Koestner, R., \& Ryan, R. M. (1999). A meta-analytic review of experiments examining the effects of extrinsic rewards on intrinsic motivation. Psychological Bulletin, 125(6), 627-668. https://doi.org/10.1037 /0033-2909.125.6.627.

Dresel, M. (2004). Motivationsförderung im schulischen Kontext. (Motivation support in the school context). Göttingen: Hogrefe.

Eccles, J. S. (1984). Sex differences in achievement: A test of alternate theories. Journal of Personality and Social Psychology, 46, 26-43.

Eccles, J. S., \& Wigfield, A. (2002). Motivational beliefs, values, and goals. Annual Review of Psychology, 53(1), 109-132. https://doi.org/10.1146/annurev.psych.53.100901.135153.

Eccles, J. S., Adler, T. F., Futterman, R., Goff, S. B., Kaczala, S. B., Meece, J. L., \& Midgley, C. (1983). Expectancies, values, and academic behaviors. In J. T. Spence (Ed.), Achievement and achievement motivation (pp. 75-146). San Francisco, CA: Freeman.

Field, A. (2013). Discovering statistics using IBM SPSS Statistics (4th ed.). London: Sage.

Fredricks, J. A., Blumenfeld, P. C., \& Paris, A. H. (2016). School engagement: potential of the concept, state of the evidence: review of educational research. https://doi.org/10.3102/00346543074001059.

Gorges, J., Schwinger, M., \& Kandler, C. (2013). Linking University students' willingness to learn to their recollections of motivation at secondary school. Europe's Journal of Psychology, 9(4), 764-782. https://oi. org/10.5964/ejop.v9i4.638. 
Guay, F., Ratelle, C. F., \& Chanal, J. (2008). Optimal learning in optimal contexts: the role of self-determination in education. Canadian Psychology/Psychologie Canadienne, 49(3), 233-240. https://doi.org/10.1037 /a0012758.

Haas, A. (2005). Unterrichtsplanung im Alltag von Lehrerinnen und Lehrern. (Lesson planning in the everday life of teachers). In A. A. Huber (Ed.), Vom Wissen zum Handeln: Ansätze zur Überwindung der TheoriePraxis-Kluft in Schule und Erwachsenenbildung (pp. 3-20). Tübingen: Ingeborg Huber Verlag.

Helsper, W. (2002). Wissen, Können, Nicht-Wissen-Können: Wissensformen des Lehrers und Konsequenzen für die Lehrerbildung. (Knowledge, Know-How, not being able to know: Knowledge forms of teachers and consequences for teacher training). In G. Breidenstein, W. Helsper, \& C. KöttersKönig (Eds.), Die Lehrerbildung der Zukunft-Eine Streitschrift (pp. 67-86). https://doi.org/10.1007 /978-3-322-80881-3 7.

Heyder, A., Bergold, S., \& Steinmayr, R. (2018). Teachers' knowledge about intellectual giftedness: a first look at levels and correlates. Psychology Learning \& Teaching, 17(1), 27-44.

Howell, J. L., Collisson, B., \& King, K. M. (2014). Physics envy: psychologists' perceptions of psychology and agreement about core concepts. Teaching of Psychology, 41(4), 330-334.

Joram, E., \& Anthony J. G. (1998). Preservice teachers' prior beliefs: Transforming obstacles into opportunities. Teaching and Teacher Education, 14 (2), 175-191. https://doi.org/10.1016/S0742-051X(97)00035-8

Kaplan, A., Katz, I., \& Flum, H. (2012). Motivation theory in educational practice: knowledge claims, challenges, and future directions. In K. R. Harris, S. Graham, T. Urdan, S. Graham, J. M. Royer, \& M. Zeidner (Eds.), APA handbooks in psychology. APA educational psychology handbook, Vol. 2. Individual Differences and Cultural and Contextual Factors (pp. 165-194). https://doi.org/10.1037 /13274-007.

Klauer, K., \& Leutner, D. (2007). Lehren und Lernen. Einführung in die Instruktionspsychologie. (Teaching and Learning. Introduction to instructional psychology.) Weinheim: Beltz.

König, J. (2010). Längsschnittliche Erhebung pädagogischer Kompetenzen von Lehramtsstudierenden (LEK): Theoretischer Rahmen, Fragestellungen, Untersuchungsanlage und erste Ergebnisse zu Lernvoraussetzungen von angehenden Lehrkräften. (Longitudinal survey of pedagogical competences of preservice teachers: Theoretical framework, questions, research design, and first restults on learning conditions of preservice teachers). Lehrerbildung auf dem Prüfstand, 3(1), 56-83.

König, J., Blömeke, S., \& Doll, J. (2011). Pädagogisches Wissen von Deutsch-, Englisch- und Mathematiklehramtsstudierenden. (Pedagogical knowledge of German, English, and Mathematics preservice teachers). In Kompetenzen von Lehramtsstudierenden in gering strukturierten Domänen: Erste Ergebnisse aus TEDS-LT (pp. 135-158). Münster: Waxmann.

Kunina-Habenicht, O., Lohse-Bossenz, H., Kunter, M., Dicke, T., Förster, D., Gößling, J., Schulze-Stocker, F., Schmeck, A., Baumert, J., Leutner, D., \& Terhart, E. (2012). Welche bildungswissenschaftlichen Inhalte sind wichtig in der Lehrerbildung? Ergebnisse einer Delphi-Studie. (Which educative contents are important in teacher training? Results of a delphi study). Zeitschrift für Erziehungswissenschaft, 15(4), 649-682. https://doi.org/10.1007/s11618-012-0324-6.

Kunter, M. (2011). Motivation als Teil der professionellen Kompetenz-Forschungsbefunde zum Enthusiasmus von Lehrkräften. (Motivation as a part of professional competence - Research findings on teacher enthusiasm). In M. Kunter, J. Baumert, W. Blum, U. Klusmann, S. Krauss, \& M. Neubrand (Eds.), Professionelle Kompetenz von Lehrkräften. Ergebnisse des Forschungsprogramms COACTIV (pp. 259-275). Waxmann: Münster.

Kunter, M., Baumert, J., Blum, W., Klusmann, U., Krauss, S., \& Neubrand, M. (Eds.). (2011). Professionelle Kompetenz von Lehrkräften - Ergebnisse des Forschungsprogramms COACTIV. (Professional competence of teachers - results of the research programme COACTIV). Münster: Waxmann.

Peter, J., Leichner, N., Mayer, A.-K., \& Krampen, G. (2015). A short test for the assessment of basic knowledge in psychology. Psychology Learning \& Teaching, 14(3), 224-235.

Pintrich, P. R. (2003). A motivational science perspective on the role of student motivation in learning and teaching contexts. Journal of Educational Psychology, 95(4), 667-686. https://doi.org/10.1037/00220663.95.4.667.

Raufelder, D. (2018). Grundlagen schulischer Motivation. (Basics of school motivation). Opladen: Barbara Budrich.

Reeve, J. (1996). Motivating others: nurturing inner motivational resources. Boston: Allyn and Bacon.

Reeve, J. (2009). Why teachers adopt a controlling motivating style toward students and how they can become more autonomy supportive. Educational Psychologist, 44(3), 159-175. https://doi.org/10.1080 /00461520903028990. 
Ross, L. (1977). The intuitive psychologist and his shortcomings: distortions in the attribution process. In L. Berkowitz (Ed.), Advances in experimental social psychology (Vol. 10, pp. 173-220). New York, NY: Academic Press.

Ryan, R. M., \& Deci, E. L. (2000). Self-determination theory and the facilitation of intrinsic motivation, social development, and well-being. American Psychologist, 55(1), 68-78. https://doi.org/10.1037/0003-066X.55.1.68.

Ryan, R. M., \& Deci, E. L. (2017). Self-determination theory: basic psychological needs in motivation, development, and wellness. New York, NY: Guilford Press.

Ryan, R. M., \& Deci, E. L. (2020). Intrinsic and extrinsic motivation from a self-determination theory perspective: definitions, theory, practices, and future directions. Contemporary Educational Psychology., 61, 101860. https://doi.org/10.1016/j.cedpsych.2020.101860.

Schunk, D. H., Meece, J. L., \& Pintrich, P. R. (2014). Motivation in education: theory, research and applications. Harlow: Pearson Education Limited.

Standing Conference of the Ministers of Education and Cultural Affairs (Kultusministerkonferenz) (Ed.). (2019). Standards für die Lehrerbildung: Bildungswissenschaften. Beschluss der Kultusministerkonferenz vom 16.12.2004 i.d.F. vom 16.05.2019. (Standards for teacher training: Education sciences, resolution of the Standing Conference of the Ministers of Education and Cultural Affairs of 16.12.2004 as amended by 16.05.2019) Retrieved from https://www.kmk. org/fileadmin/veroeffentlichungen_beschluesse/2004/2004_12_16-Standards-LehrerbildungBildungswissenschaften.pdf

Steinmayr, R., \& Spinath, B. (2009). The importance of motivation as a predictor of school achievement. Learning and Individual Differences, 19(1), 80-90. https://doi.org/10.1016/j.lindif.2008.05.004.

Syring, M. (2018). Motivierung. In E. Kiel (Ed.), Unterricht sehen, analysieren, gestalten (Seeing, analyzing, and designing teaching) (3rd ed., pp. 37-62). Bad Heilbrunn: Julius Klinkhardt.

Taheri, Z. (2011). An investigation of the effective factors on students' motivational beliefs: the case of Iranian students. Europe's Journal of Psychology, 7(1), 62-80. https://doi.org/10.5964/ejop.v7i1.105.

Tas, Y. (2016). The contribution of perceived classroom learning environment and motivation to student engagement in science. European Journal of Psychology of Education, 31(4), 557-577. https://doi. org/10.1007/s10212-016-0303-z.

van Buer, J., \& Petzold-Rudolph, K. (2015). Die "neue” Lehrerbildung in Deutschland. Vom Praxisschock zur aufgeklärten Aneignung professionellen Handelns? - Lehrerbildung als systemischer Teil der Bildungsreform. ("New" teacher education in Germany. From reality shock to sophisticated acquisition of professional action? - teacher education as a systemic part of education reform). International Journal for 21st Century Education, 2, 9-38.

Vogel, T. (2011). Zum Theorie-Praxis-Verhältnis in der Lehrerbildung als Übergangsproblem. (On the theorypractice-relation in teacher training as a transition problem).Bwp@, (Spezial 5 - Hochschultage Berufliche Bildung 2011. Fachtagung 03.), 1-13.

Voss, T., \& Kunter, M. (2011). Pädagogisch-psychologisches Wissen von Lehrkräften. (Pedagogical-psychological knowledge of teachers). In M. Kunter, W. Blum, U. Klusmann, S. Krauss, \& M. Neubrand (Eds.), Professionelle Kompetenz von Lehrkräften. Ergebnisse des Forschungsprogramms COACTIV (pp. 193214). Waxmann: Münster.

Voss, T., Kunina-Habenicht, O., Hoehne, V., \& Kunter, M. (2015). Stichwort Pädagogisches Wissen von Lehrkräften: Empirische Zugänge und Befunde. (Keyword pedagogical knowledge of teachers: empirical approaches and results). Zeitschrift für Erziehungswissenschaft, 18(2), 187-223. https://doi.org/10.1007 /s11618-015-0626-6.

Weiner, B. (1985). An attributional theory of achievement motivation and emotion. In A. Attributional (Ed.), Theory of Motivation and Emotion (Vol. 92, 4th ed., pp. 548-573). New York, NY: Springer.

Weiner, B. (1992). Human motivation: metaphors, theories, and research. London: Sage.

Weiner, B. (2018). The legacy of an attribution approach to motivation and emotion: a no-crisis zone. Motivation Science, 4(1), 4-14.

Weiner, B., Frieze, I., Kukla, A., Reed, L., Rest, S., \& Rosenbaum, R. M. (1971). Perceiving the causes of success and failure. New York, NY: General Learning Press.

Wentzel, K. R. \& Wigfield, A. (2009). Handbook of Motivation at School. New York: Routledge.

Wigfield, A., \& Wentzel, K. R. (2007). Introduction to motivation at school: interventions that work. Educational Psychologist, 42(4), 191-196. https://doi.org/10.1080/00461520701621038.

Wigfield, A., Eccles, J. S., Schiefele, U., Roeser, R. W., \& Davis-Kean, P. (2007). Development of achievement motivation. In Handbook of Child Psychology. https://doi.org/10.1002/9780470147658.chpsy0315.

Wigfield, A., Tonks, S., \& Klauda, S. L. (2009). Expectancy-value theory. In K. R. Wentzel \& A. Wigfield (Eds.), Handbook of Motivation at School. New York, NY: Routledge. 
Linda Schürmann. University of Koblenz-Landau, Institute of Psychology, Koblenz, Germany. E-mail: lschuerm@uni-koblenz.de

\section{Current themes of research:}

Motivation. Self-determination theory. Preservice teachers. Extracurricular learning settings. Digital learning. Digital teaching. Mental rotation.

Most relevant publications in the field of Psychology of Education:

No previous publications

Robert Gaschler. FernUniversität in Hagen, Faculty of Psychology, Hagen, Germany.

Current themes of research:

Knowledge acquisition with text and (data)graphs. Effects of (self)testing in online learning environments. Motivational effects of conveying psychological knowledge about learning and forgetting.

Most relevant publications in the field of Psychology of Education:

Blech, C. \& Gaschler, R. (2017). Developing a drawing task to differentiate group average time course vs. dynamics in the individual. Psychology Learning \& Teaching, 16(2), 212-231. doi: 10.1177/ 1475725717700516

Blech, C., \& Gaschler, R. (2018). Assessing students' knowledge about learning and forgetting curves with a free production technique: measures and implications for the development of learning aids. Psychology Learning \& Teaching, 17(3), 308-322. doi: 10.1177/1475725718779684

Zhao, F., Schnotz, W., Wagner, I., \& Gaschler, R. (2019). Texts and pictures serve different functions in conjoint mental model construction and adaptation. Memory \& Cognition. doi:10.3758/s13421-019-00962-0

Claudia Quaiser-Pohl. University of Koblenz-Landau, Institute of Psychology, Koblenz, Germany.

Current themes of research:

Mental rotation - assessment, development, and gender differences. Enhancement of mathematical and scientific abilities in early childhood. Enhancement of reading and writing abilities in primary school children. Psychological assessment and development from a cross-cultural perspective. Empowerment of women in the STEM field.

Most relevant publications in the field of Psychology of Education:

Motivation theory in the school context: differences in preservice and practicing teachers' experience, opinion, and knowledgeDiversity in education and the concept of "diversity" as a topic for educational science studies. In C. Quaiser-Pohl, V. R. Ruthsatz, \& M. Endepohls-Ulpe (Eds), Diversity and Diversity Management in Education - A European Perspective (pp. 9-22). Münster/New York: Waxmann.

Quaiser-Pohl, C. \& Endepohls-Ulpe, M. (Hrsg.). (2010). Bildungsprozesse im MINT-Bereich. Interesse, Partizipation und Leistungen von Mädchen und Jungen. Münster: Waxmann.

Quaiser-Pohl, C., Köhler, A. \& Sticker, E. (2012). Mathematisch begabt. Vorschulkinder angemessen fördern. Göttingen: Vandenhoeck \& Ruprech

Sander, E., Quaiser-Pohl, C., \& Endepohls-Ulpe, M. (2019). Mentoring als Kernelement der Frauenförderung im MINT-Bereich. Das rheinland-pfälzische "Ada-Lovelace-Projekt". (Mentoring as a core element in the promotion of women in the STEM-context. The Rhineland-Palatinate ,Ada-Lovelace-project"). In Y. Hafner \& L. Loge (Hrsg.), Berufsorientierung für Frauen im MINT-Bereich (pp. 164-182). Leverkusen: Verlag Barbara Budrich.

Publisher's note Springer Nature remains neutral with regard to jurisdictional claims in published maps and institutional affiliations. 